\title{
Pelatihan dan Pendampingan Akuntansi Computer dan Aplikasi Perkantoran dengan Menggunakan Microsoft Excel untuk Meningkatkan Capability Himpunan Wanita Disabilitas (HWDI) Kabupaten Lombok Barat
}

\author{
Khalid Abjadi*, Titiek Herwanti, Endar Pituringsih \\ Fakultas Ekonomi dan Bisnis Universitas Mataram, Mataram, Indonesia
}

\author{
Article history \\ Received: 08-11-2021 \\ Revised: 17-11-2021 \\ Accepted: 24-11-2021 \\ *Corresponding Author: \\ Khalid Abjadi, \\ Fakultas Ekonomi dan \\ Bisnis Universitas \\ Mataram, Mataram, \\ Indonesia; \\ Email: \\ abjadik1993@gmail.com
}

\begin{abstract}
Disabled empowerment is a process in which people with disabilities are given knowledge and skills training to live independently. The purpose of this activity is to improve the ability and skills of managers and members of HWDI in West Lombok Regency. The activity is carried out by holding training and assistance in computer accounting and office accounting using Microsoft Excel, the results of the implementation of this activity are expected to improve the capabilities of managers and members of HWDI. In addition, this training and assistance is carried out to provide new abilities and skills to managers and members of HWDI, so they can take advantage of digitalization opportunities to improve the economy of people with disabilities. This training and mentoring activity will be aimed at managers and members of HWDI in West Lombok Regency. The implementation of the activities is carried out with an approach to providing material and mentoring computer accounting training and office accounting using Microsoft Excel. The results of counseling and training activities on computer accounting and office accounting in increasing the knowledge and capability of the management and members of the West Lombok Regency HWDI are useful and supported by the management and members, so that in the future they can remain independent.
\end{abstract}

Keywords: disabled empowerment; abilities; skills; economy

Abtrak: Pemberdayaan difabel adalah proses di mana difabel diberikan pengetahuan dan pelatihan keterampilan untuk hidup mandiri. Tujuan dilakukannya kegiatan ini adalah untuk meningkatkan kemampuan dan keterampilan pengelola dan anggota HWDI kabupaten lombok barat. Kegiatan dilakukan dengan mengadakan pelatihan dan pendampingan akuntansi komputer dan akuntansi perkantoran dengan menggunakan microsoft excel, hasil pelaksanaan kegiatan ini diharapkan dapat meningkatkan kapabilitas pengelola dan anggota HWDI. Selain itu, pelatihan dan pendampingan ini dilakukan untuk memberikan kemampuan dan keterampilan baru kepada pengelola dan anggota HWDI, sehingga dapat memanfaatkan peluang digitalisasi untuk meningkatkan perekonomian para penyandang disabilitas. Kegiatan pelatihan dan pendampingan ini akan ditujukan pada pengelola dan anggota HWDI kabupaten lombok barat. Pelaksanaan kegiatan dilakukan dengan pendekatan pemberian materi dan pendampingan pelatihan akuntansi komputer dan akuntansi perkantoran dengan menggunakan microsoft excel. Hasil kegiatan penyuluhan dan pelatihan tentang akuntansi computer dan akuntansi perkantoran dalam meningkatkan pengetahuan dan capability pengurus dan anggota HWDI Kabupaten Lombok Barat, bermanfaat dan didukung oleh pengurus dan anggota, sehingga kedepannya tetap bisa mandiri.

Kata Kunci: : pemberdayaan difabel; kemampuan; keterampilan; perekonomian 


\section{PENDAHULUAN}

Secara perundang-undangan, terdapat dua undang-undang utama yang terkait dengan para penyandang disabilitas di Indonesia: UU No. 4 tahun 1997 tentang Penyandang Cacat dan peraturan untuk pelaksanaannya, yaitu Peraturan Pemerintah No. 43 tahun 1998 (tentang Upaya Peningkatan Kesejahteraan Sosial Penyandang Cacat). Akan tetapi, kurangnya perhatian dan masih adanya diskriminasi terhadap para penyandang disabilitas di Indonesia masih dalam mengakar pada stigma serta persepsi yang tidak tepat terkait dengan kemampuan para penyandang disabilitas di dalam menjalankan kegiatan sehari-hari mereka, termasuk di dalamnya juga terkait dengan kontribusi yang mereka berikan secara aktif di semua sektor ekonomi. Undang-Undang Republik Indonesia Nomor 8 Tahun 2016 tentang Penyandang Disabilitas disahkan oleh Presiden Joko Widodo pada tanggal 15 April 2016. Agar seantero negara Indonesia mengetahuinya, UU 6 tahun 2016 tentang Penyandang Disabilitas diundangkan dan ditempatkan dalam Lembaran Negara Republik Indonesia Tahun 2016 Nomor 69 dan Penjelasan Atas UU 8 Tahun 2016 tentang Penyandang Disabilitas ditempatkan dalam Tambahan Lembaran Negara Republik Indonesia Nomor 5871 oleh Menteri Hukum dan Hak Asasi Manusia Yasonna H. Laoly pada hari itu juga tanggal 15 April 2016 di Jakarta.

Di Indonesia, terminologi lain yang digunakan untuk menyebut difable ini antara lain adalah penyandang cacat, orang berkelainan, atau orang tidak normal. Istilah tersebut sebenarnya tidak bebas nilai, artinya ada konsepsi nilai tertentu yang telah dipaksakan oleh sekelompok masyarakat tertentu yang melabelkan dan mendominasi kelompok masyarakat lain. Peristilahan ini berpengaruh secara langsung

terhadap perlakuan masyarakat maupun pemerintah terhadap keberadaan difable secara menyeluruh (Harahap et al. 2015). Disabilitas merupakan isu yang (seharusnya) sangat familiar bagi masyarakat umum, karena merupakan bagian dari kondisi manusia dan memiliki prevalansi yang tinggi. Faktanya, hampir setiap individu pernah mengalami disabilitas pada salah satu fase kehidupannya. Bagi orang yang mencapai usia yang panjang, kemungkinan besar akan mengalami kesulitan terkait keberfungsian fisik dan sosialnya. Selain itu, mayoritas keluarga luas (extended family) memiliki paling tidak seorang anggota yang menjadi penyandang disabilitas dan di sisi lain, banyak individu non-penyandang disabilitas melakukan keluarga, sanak saudara atau teman penyandang disabilitas (Syafi'ie, 2014).

Implementasi pemberdayaan ekonomi bagi penyandang disabilitas mendasarkan

pada peraturan perundang-undangan dan kebijkan yang telah ada baik ditingkat internasional, regional, nasional dan daerah. Implementasi pemebrdayaan kepada penyandang disabilitas di Indonesia masih banyak menjumpai persoalan yang memerlukan pembenahan diberbagai sisi. Dan faktor yang paling dominan mendukung suksesnya pemberdayaan ekonomi bagi penyandang disabilitas adalah adanya motivasi dari penyandang disabilitas, adanya dukungan keluarga, adanya kesesuaian antara minat dan kapasitas yang dimiliki dalam pemilihan bidang yang ditempuh, adanya peralatan dan modal, adanya pendampingan baik pada pemasaran dan pengembangan produk, adanya jaringan kerja yang mendukung dalam masyarakat, adanya lembaga pendampingan pengembangan karier pada penyandang disabilitas yang masuk ke pasar tenaga kerja (Surwanti, 2014).

Lembaga HWDI adalah lembaga non-profit yang dibentuk oleh sekumpulan wanita disabilits dan wanita pemerhati masalah disabilitas, yang terikat atas dasar kesamaan kepentingan dan keserasian dalam usaha dibidang pemberdayaan untuk mengatasi masalah yang dihadapi oleh penyandang disabilitas khusunya wanita disabilitas guna mencapai suatu maksud dan tujuan yang sama. Penyandang disabilitas di Lombok Barat sendiri menurut data tahun 2018 lalu total berjumlah 2.425 orang. Sebanyak 327 orang adalah penyandang disabilitas tubuh, sisanya mereka yang mengalami disabilitas netra, ganda, rungu wicara, psikotik, dan grahita. Mereka memiliki kebutuhan 
khusus yang juga harus diperhatikan oleh pemerintah. Tidak hanya menyiapkan fasilitas ramp di kantor-kantor pelayanan, namun juga trotoar dan rambu jalan yang sesuai dengan kondisi mereka (Humas Lobar).

Perusahaan atau organisasi bisnis bisa menggunakan software akuntansi untuk memudahkan mereka dalam pembuatan laporan keuangan. Penggunaan software accounting sangat diperlukan oleh perusahaan-perusahaan baik perusahaan besar maupun perusahaan kecil atau organisasi bisnis untuk lebih mempermudah melakukan proses-proses akuntansi seperti penjurnalan, pembuatan laporan keuangan, penyusunan daftar gaji, laporan laba/rugi dll. Didasari oleh maraknya penggunaan software atau perangkat lunak akuntansi ini, tiap-tiap software memiliki kelebihan dan kekurangan, pengembang software pun berlomba-lomba untuk menyediakan software yang terbaik untuk perusahaan-perusahaan tersebut. Software yang ada pun semakin berkembang pesat dan semakin mudah untuk digunakan (Dwijayanti \& Suharyati, 2013).

Software akuntansi dan microsft excel sama-sama menyediakan fasilitas yang baik. Jika menggunakan software akuntansi lebih cepat, mudah, tidak perlu memikirkan rumus karena sudah ada di dalam sistem, cukup sekali klik maka jurnal, buku besar, laporan keuangan, rasio keuangan, revaluasi valas, rekonsiliasi bank, depresiasi harta tetap, dan grafik analisis bisnis langsung jadi. Sedangkan jika menggunakan microsoft excel harus membuat rumus terlebih dahulu, sukarnya menjurnal transaksi yang rumit dengan perhitungan diskon bertingkat dan biaya HPP, harus menghitung manual depresiasi harta tetap, menghitung manual rasio keuangan, dll. Jadi kesimpulannya software akuntansi dan microsoft excel sama-sama baik dan memiliki fungsinya masing-masing yang unik. Tetapi, semakin kompleks aktivitas transaksi, semakin tinggi pula kebutuhan kita terhadap software akuntansi tentunya (Larosa \& Berupilihen, 2009).

Persoalan yang dihadapi para wanita disabilitas ini sulit mengeoperasikan komputer. Para wanita disabilitas juga belum mahir dalam menggunakan program standar pada komputer terutama miscrosoft excel. Padahal kebutuhan akan pemahaman terkait komputer diperlukan oleh wanita disabilitas untuk menunjang kegiatan administrasi dan pengelolaan keuangan. Selain itu juga tidak adanya tenaga pendidik yang mampu untuk mengajari para wanita disabilitas untuk menguasai keterampilan komputer.

Kegiatan ini diharapkan dapat meningkatkan kemampuan para peserta pelatihan, sehingga dengan meningkatnya kemampuan mereka mampu meningkatkan kesejahteraan para penyandang disabilitas. Melalui pelatihan ini diharapkan peserta disabilitas memiliki kemampuan mengoperasikan komputer setara dengan yang lain. Dengan bekal keterampilan komputer ini penyandang disabilitas kelak diharapkan memiliki kemandirian, baik untuk mendapatkan pekerjaan formal maupun berwirausaha dalam rangka peningkatan kesejahteraan mereka. Berdasarkan analisis situasi diatas, maka dapat dirumuskan permasalahan sebagai berikut: 1) Diperlukan kegiatan dan pelatihan yang akan menambah wawasan dan pengetahuan baru, khususnya akuntansi komputer dan akuntansi perkantoran dengan menggunakan microsoft excel, dan 2) Pendapingan penyusunan pelaporan atau pembukuan yang masih belum memadai karena keterbatasan personal untuk berbagi pengetahuan dan keterampilan dalam menggunakan microsoft excel.

\section{METODE}

Kegiatan pengabdian dilakukan di Himpunan Wanita Disabilitas (HWDI) Kabupaten Lombok Barat pada hari Sabtu 04 September 2021 pada pukul 13.00-17.00 Wita. Peserta pengabdian dihadiri oleh 20 peserta Himpunan Wanita Disabilitas (HWDI) Kabupaten Lombok Barat. Sebelum kegiatan 
pengabdian dilakukan, tim pengabdian telah melakukan pemberitahuan informasi secara langsung kepada pengurus HWDI Lobar yang kemudian disampaikan pada setiap anggota HWDI Lobar.

Adapun metode pelaksanaan kegiatan Pengabdian Pada masyarakat ini dilakukan dengan metode Ceramah,

tutorial, dan diskusi. Dengan langkah-langkah kegiatan sebagai berikut :

1. Langkah 1 (Metode Ceramah)

Peserta diberikan penyuluhan tentang pedoman penggunaan akuntansi komputer dan akuntansi perkantoran menggunakan microsoft excel untuk Pengurus dan anggota Himpunan Wanita Disabilitas (HWDI) kabupaten Lombok Barat.

2. Langkah 2 (Metode Tutorial)

Peserta pelatihan diberikan pelatihan pendampingan tentang akuntansi komputer dan akuntansi perkantoran menggunakan microsoft excel dengan praktek secara langsung.

3. Langkah 3 (Metode Diskusi)

Peserta diberikan kesempatan untuk menyampaikan dan mendiskusikan permasalahan yang dihadapi dalam penggunaan akuntansi komputer dan akuntansi perkantoran menggunakan microsoft excel.

\section{HASIL DAN PEMBAHASAN}

Materi kegiatan yang disampaikan adalah akuntansi computer dan aplikasi perkantoran dengan menggunakan microsoft excel kepada peserta. Kegiatan ini dilaksanakan dengan mengikuti protocol kesehatan yang berlaku disaat pandemi covid-19. Hasil pelaksanaan sosialisasi secara garis besar dilaporkan berikut ini.

\section{a. Peserta Yang Hadir}

Seluruh peserta yang diundang datang untuk menghadiri kegiatan ini. Dengan demikian target peserta yang hadir terpenuhi $100 \%$.

\section{b. Ketercapaian Target Kegiatan}

Dalam pelaksanaan kegiatan ini, kepada peserta diberikan materi terkait dengan akuntansi computer dan aplikasi perkantoran dengan menggunakan microsoft excel. Seluruh materi dapat diterima, dicerna dan dipahami peserta dengan baik. Jumlah peserta proporsional dengan jumlah anggota tim pengabdi yang berperan sebagai narasumber turut menunjang pelaksanaan sosialisasi menjadi lebih kondusif. Hal ini didukung oleh antusiasme peserta untuk mengikuti kegiatan ini hingga berakhir. Dilihat dari ketercapaian target tujuan sosialisasi, dapat dinilai baik (90\%) ditunjukkan oleh peningkatan pemahaman peserta.

\section{c. Ketercapaian Target Materi}

Pelaksanaan kegiatan melibatkan seluruh anggota tim pengabdian kepada masyarakat yang terdiri dari 3 (tiga) orang. Sesi tanya jawab dilakukan bersamaan dengan penyajian materi. Peserta dapat secara langsung mengajukan pertanyaan ataupun menyampaikan pengalaman yang berkaitan dengan komputer.

\section{d. Faktor Penghambat}

1. Kondisi pandemic covid-19 mengharuskan kegiatan ini dilangsungkan dengan menerapkan protocol kesehatan yang berlaku. Semua yang terlibat diharuskan menggunakan masker dan menggunakan hand sanitizer yang disediakan tim pengabdi kepada masyarakat.

2. Kurangnya computer/laptop yang memadai dalam kegiatan ini. Dimana peserta menggunakan 1 (satu) computer/laptop dengan dua atau tiga orang peserta. 


\section{e. Faktor Pendukung}

1. Komitmen dan antusiasme peserta yang tinggi untuk menghadiri kegiatan ini ditengah pandemic covid-19 sangat menggembirakan bagi tim pengabdian kepada masyarakat.

2. Adanya dukungan dari ketua HWDI Lombok Barat sangat membantu terlaksananya kegiatan ini.

3. Kesediaan Lembaga HWDI Lombok Barat untuk menyediakan tempat bagi terselenggaranya kegiatan ini sangat membantu tim pengabdian kepada masyarakat.

4. Komunikasi di antara anggota tim berlangsung lancar dan efektif sehingga koordinasi tim pada proses persiapan, pembagian materi, dan pelaksanaan sosialisasi dapat berlangsung sesuai rencana.
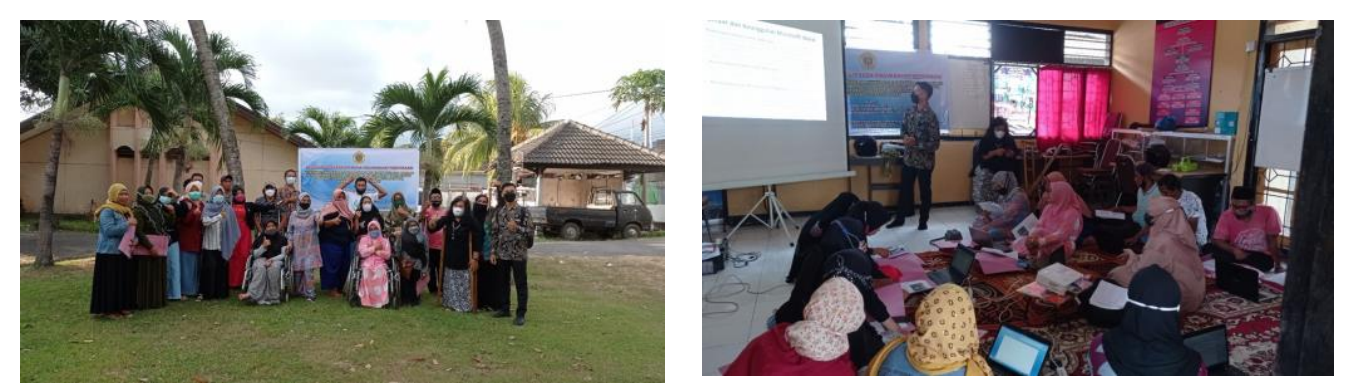

Gambar Kegiatan Pengabdian tentang Akuntansi Komputer dan Aplikasi Perkantoran Dengan Menggunakan Microsoft Excel HWDI Kabupaten Lombok Barat

\section{KESIMPULAN DAN SARAN}

Hasil kegiatan penyuluhan dan pelatihan tentang akuntansi computer dan akuntansi perkantoran dalam meningkatkan pengetahuan dan capability pengurus dan anggota Himpunan Wanita Disabilitas (HWDI) Kabupaten Lombok Barat. Indikator keberhasilan yang digunakan dalam kegiatan ini yaitu tingkat kehadiran peserta pengabdian yang sangat tinggi, animo yang besar untuk mengikuti kegiatan, tanya jawab yang aktif serta interaksi dua arah yang baik antara tim pengabdian dan peserta selama proses diskusi berlangsung. Oleh karena itu, kegiatan penyuluhan dan pelatihan ini diharapkan selalu dapat dilakukan sehingga membantu memberikan pemahaman yang lebih baik terkait akuntansi computer dan aplikasi perkantoran. Beberapa hal yang masih kurang baik dalam pelaksanaannya akan ditingkatkan pada kegiatan mendatang.

\section{Ucapan Terima Kasih}

Tim pengabdian mengucapkan terima kasih kepada Lembaga Penelitian dan Pengabdian kepada Masyarakat (LPPM), Badan Pengkajian dan Pengembangan Ekonomi dan Bisnis (BP2EB), dan Fakultas Ekonomi dan Bisnis melalui sumber dana BLU (PNBP) Universitas Mataram yang telah memberi kesempatan dan bantuan kepada tim pengabdian untuk melakukan kegiatan ini

\section{DAFTAR PUSTAKA}

Dwijayanti, R. \& Suharyati. (2013). Pembuatan Laporan Keuangan dengan Microsoft Excel. Yogyakarta: Skripta

Harahap, R. R. \& Bustanudin, M. (2015). Perlindungan Hukum Terhadap Penyandang Disabilitas Menurut 
Convention On The Rights Of Persons With Disabilities (CRPD). Jurnal Inovatif Volume VIII Nomor 1 Januari 2015.

Larosa, F. G. N. \& Berupilihen, B. G. (2009). Microsoft Excel for Accounting Cycle. Yogyakarta: Andi Publisher

Maharani, A. E. P., \& Isharyanto (2014). Pembadanan (Embodying) Kebijakan Berbasis Kapasitas dalam Pemberdayaan Difabel Untuk Penanggulangan Kemiskinan. Jurnal Dinamika Hukum.

Margaretha, M. (2015). Disabilitas dalam Ketangguhan: Berangkat dari Sumberdaya yang Belum Termanfaatkan. German: Aktion Deutschland Hilft

Suharto, E. (2014). Membangun Masyarakat Memberdayakan Rakyat. Bandung: Refika Adhitama. Syafi'ie, M. (2014). Pemenuhan Aksesibilitas Bagi Penyandang Disabilitas. Jurnal Inklusi.

Surwanti, A. (2014). Model Pemberdayaan Ekonomi Penyandang Disabilitas di Indonesia. Jurnal Manajemen \& Bisnis.

Syafi'ie, M. (2014). Pemenuhan Aksesibilitas Bagi Penyandang Disabilitas. Inklusi Volume 1, Nomor 2 Juli-Desember 2014.

To'atin (2019). Strategi Lembaga Himpunan Wanita Disabilitas Indonesia (HWDI) dalam Pemberdayaan Wanita Disabilitas di Jakarta Pusat. Fakultas Dakwah dan Ilmu Komunikasi Universitas Islam Negeri Raden Intan Lampung.

Undang-undang Nomor 8 Tahun 2016 tentang Penyandang Disabilitas

Undang-undang Nomor 9 Tahun 1998, tentang Kemerdekaan Menyampaikan Pendapat Dimuka Umum. 